\title{
The essence of future smart houses: from embedding ICT to adapting to sustainability principles
}

\begin{abstract}
In the context of intelligent environments, the smart houses are often pointed as one of the main constituents of smarter living environments. This study attempts to theoretically analyze case models of smart houses in order to identify their essence and characteristics. The results show that the most significant intelligent values embodied in smart houses embrace technologies of the functional automation. In fact, smart houses are substantially intertwined with integrated ICT technologies which aim to ensure comfortable living environments. Despite the identified challenges, the proliferation of smart houses into urban areas requires an integration of them in the city for creating intelligent environments. As a result, the promotion and integration of smart houses with other smarter elements of cities could archive a significant enhancement of the quality of life and a stronger urban sustainability.
\end{abstract}

Keyword: Smart house; Intelligent building design; Smart city; Intelligent technological values 